\title{
Interação da torra e moagem do café na preferência do consumidor do oeste paranaense
}

\author{
Influence of roasting and milling on consumers coffee preference at Paraná west-Brazil
}

\author{
Carla Adriana Pizarro Schmidt ${ }^{\mathrm{I}}$ Édison Miglioranza ${ }^{\mathrm{II}}$ Sandra Helena Prudêncio ${ }^{\mathrm{III}}$
}

\section{RESUMO}

O objetivo deste estudo foi avaliar as preferências dos consumidores de café da região oeste do Paraná, em relação ao ponto de torra e à granulometria de moagem. Foram realizadas análises sensoriais de preferência e físicoquímicas. As análises físico-químicas foram utilizadas para monitorar as mudanças ocorridas nos produtos ao longo do processo de torra. Os cafés com torras mais leves foram pouco aceitos. O café que apresentou aparência global, aroma e sabor preferido foi o que apresentava uma torra média escura, mais próxima das torras tradicionais brasileiras. A torra mais escura foi bem aceita apenas em relação à aparência. A moagem fina foi preferida em relação à aparência global do produto, mas, apesar de ter apresentado maior acidez, os provadores não diferenciaram seu sabor.

Palavras-chave: Coffea arabica, qualidade de bebida, propriedades físicas, propriedades químicas.

\section{ABSTRACT}

This study aimed the evaluation of the consumers preference for coffee in the west region of Paraná State, Brazil, in relation to the roasting degree and grinding granulometry. Sensorial preference and physical-chemichal analysis were made. The physical-chemichal analysis were used to monitor the changes that occurred in the products along the roasting process. The samples of coffee with light toasts were little accepted. The kind of coffee that presented preferred global appearance, aroma and taste was the one which presented average dark toasting, which is the one that is more similar to the traditional Brazilians toastings. The darkest toasting, was well-accepted in relation to appearance. The thin milling was preferred in relation to the global appearance of the product, but in spite of having presented major acidity the tasters did not make difference about its taste.

Key words: Coffea arabica, quality of the beverage, physical properties, chemical properties.

\section{INTRODUÇÃO}

O processo da torração pode ser descrito como sendo a passagem dos grãos de café por um aquecimento controlado para que sejam desencadeadas uma série de reações exotérmicas (formadoras do gosto e do aroma do café), sem que tais reações ultrapassem o ponto adequado e se inicie o processo de carbonização (CORTEZ, 2001). O sabor e o aroma do café, segundo SIVETZ \& DESROSIER, (1979), é resultante da combinação de centenas de compostos que são produzidos por reações pirolíticas que ocorrem durante a torrefação. Tais atributos sensoriais são devidos, em grande parte, à quebra das proteínas, com a formação de compostos aromáticos, bem como à interação dos aminoácidos derivados (SCHWARTZBERG, 1999). Complexos mecanismos bioquímicos encontram-se envolvidos na produção de características de cor, sabor e aroma do café durante a torra, como as reações de Maillard, degradação de Strecker, caramelização de açúcares, degradação de ácidos clorogênicos, proteínas e polissacarídeos (ILLY \& VIANI, 1996).

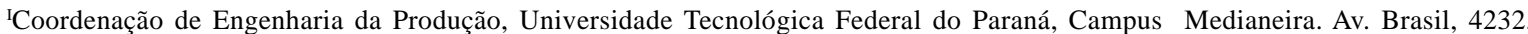
Parque Independência, 85884-000, Medianeira, PR, Brasil. E-mails: cs910@yahoo.com.br e carlaschmidt@utfpr.edu.br. Autor para correspondência.

IIDepartamento de Agronomia, Centro de Ciências Agrárias (CCA), Universidade Estadual de Londrina (UEL), Londrina, PR, Brasil.

IIIDepartamento de Tecnologia de Alimentos e Medicamentos, CCA, UEL, Londrina, PR, Brasil. 
Os cafés brasileiros caracterizam-se por apresentar, em geral, torração excessiva, com baixa qualidade de bebida. O surgimento no mercado nacional de cafés importados mais nobres tem levado ao questionamento sobre o padrão nacional de torração (MOURA et al., 2001). Cada país possui um padrão de torração característico, sendo que, no Brasil, o café torrado mais escuro deve-se não só à preferência do consumidor, mas também à necessidade de mascarar a presença de defeitos ou alterações comuns em cafés comerciais (CLARKE \& MACRAE, 1990).

Os estudos de consumidores são a base necessária para a busca de novos mercados, bem como para a modificação de aspectos dos produtos já existentes (GUERRERO, 1999). Ao estudarem a compra de café nos mercados da cidade de São Paulo, LUNA et al. (2003) identificaram que o café é comprado principalmente por mulheres casadas, havendo preferência por café em pó (torrado e moído) do Paraná. Em seu trabalho, CRISTOVAM et al. (2000) citam que existe diferença de preferência hedônica entre os sexos no grau de torra do café, sendo que as mulheres, ao contrário dos homens, mostraram maior preferência por cafés com torras mais claras. A infusão à base de torras mais claras possui maior quantidade de substâncias aromáticas, visto que esse tipo de torra volatiliza menos essas substâncias. Já as torras mais escuras fornecem infusão escura, porém com menos aroma e sabor mais amargo (DELLA MODESTA et al., 1999).

Os consumidores das dez cidades brasileiras estudadas por FARIA et al. (2000) definem a aceitabilidade do café torrado e moído com base nas características de fragrância/aroma e aspecto do pó, e consideram menos importantes os atributos de aroma e sabor da bebida. É necessário que os consumidores sejam incentivados a reconhecerem e valorizarem os diferentes padrões de bebidas e que se confiram características de uniformidade e de qualidade ao produto (PINTO et al., 2001).

O café, segundo o regulamento técnico de identidade e qualidade (BRASIL, 2003), é classificado em arábica e robusta. O grupo arábica é classificado em sete subgrupos de bebida, sendo os primeiros quatro subgrupos de bebidas finas e os três últimos de bebidas fenicadas, a saber: Estritamente Mole; Mole; Apenas Mole; Duro; Riado; Rio e Rio Zona. O grupo robusta é classificado em quatro subgrupos: Excelente; Boa; Regular e Anormal. De acordo com MORAES \& TRUGO (2001), pouco se conhece sobre a influência da granulometria do café tanto no rendimento como na qualidade da bebida, principalmente sob a forma de normas industriais. Menos ainda se sabe sobre os efeitos da combinação da granulometria com o ponto de torra sobre a qualidade e o rendimento da bebida.
O objetivo deste trabalho foi avaliar a interação de quatro diferentes tempos de torra e duas granulometrias de moagem na preferência dos consumidores de café do oeste do Estado do Paraná.

\section{MATERIAL E MÉTODOS}

Foram utilizados 20kg de grãos de café de bebida classificada como Dura, colhidos em Londrina, na safra 2003. O café foi torrado em torrefador elétrico "CANHOS”, em parcelas de $1 \mathrm{~kg}$, a uma temperatura final entre 180 e $230^{\circ} \mathrm{C}$, por 16 , 18 , 20 e 22 minutos. Posteriormente os grãos torrados foram moídos, em moedor manual, em duas granulometrias, média

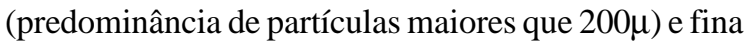
(predominância de partículas menores que $200 \mu$ ), resultando em oito amostras diferentes. O pó foi estocado em embalagens de polipropileno, numa temperatura de aproximadamente $10^{\circ} \mathrm{C}$, até o momento do preparo para as análises sensoriais (realizadas num período máximo de 15 dias) e químicas.

Foram realizadas análises químicas de acidez titulável pela metodologia da AOAC (1996) e os resultados expressos em $\mathrm{mL}$ de $\mathrm{NaOH} 0,1 \mathrm{~N}$, requerido para neutralizar a acidez de $100 \mathrm{~g}$ de amostra. $\mathrm{O}$ pH foi medido no mesmo extrato, conforme recomendado por LOPES et al. (2000). A análise de umidade foi realizada pelo método de estufa a $105^{\circ} \mathrm{C}$ até peso constante. Para análise de coloração dos pós, foi utilizado o equipamento Photovolt modelo 577, medindo-se o percentual de reflexão da luz emitida pelo aparelho. As análises químicas foram realizadas seguindo o delineamento experimental em blocos ao acaso e avaliadas pela análise de variância e teste de comparação de médias de Tukey $(\mathrm{P}<0,05)$.

Foram realizadas três análises sensoriais. A primeira foi a de ordenação da preferência em relação à aparência global com 100 consumidores em um supermercado local. As demais foram com 100 consumidores apreciadores de café, tanto para ordenação da preferência em relação ao aroma dos pós, como hedônica para as bebidas resultantes. Foram solicitadas, em todas as análises, informações sobre idade, sexo, formas e freqüência de consumo da bebida.

Na análise de aparência global, as amostras dos pós foram acondicionadas em copinhos plásticos brancos codificados e apresentados por moagem, para que os consumidores indicassem a moagem preferida de acordo com a aparência. A partir da moagem previamente escolhida, os consumidores ordenaram as amostras de acordo com a sua preferência de cor de torra. A análise sensorial do aroma dos pós foi realizada em uma sessão, sendo servidos 5 gramas de pó, de 
cada uma das quatro torras, com moagem fina, em copinhos plásticos, identificados com números de três dígitos, tampados com papel alumínio, contendo cinco furos cada. Para a análise do sabor da bebida, o café foi preparado em uma cafeteira elétrica, Mallory Cafemax, com filtro de papel e água à temperatura de $86^{\circ} \mathrm{C}$. Utilizou-se um litro de água para cada 100 gramas de pó, conforme recomendações de preparo do café da ABIC, (2004). Após o preparo, este foi estocado em garrafas térmicas com capacidade para um litro.

As oito diferentes bebidas foram degustadas em duas sessões de análise sensorial, sendo provadas quatro amostras por sessão, de forma monádica e em ordem aleatória. Para servir, utilizou-se copinhos plásticos brancos descartáveis de $50 \mathrm{~mL}$, encaixados em alças próprias para café, codificadas com números de três dígitos, contendo aproximadamente $25 \mathrm{~mL}$ de café a uma temperatura média de $55^{\circ} \mathrm{C}$. Os provadores receberam um copo de $200 \mathrm{~mL}$ com água a $25^{\circ} \mathrm{C}$, para lavar a boca antes e entre as degustações de cada uma das amostras. Uma pá plástica transparente e embalagens com açúcar foram fornecidas para que cada provador adoçasse o café segundo sua preferência. A avaliação foi realizada com base em uma escala hedônica de nove pontos, para o sabor e um teste de ordenação da preferência para os aromas. Todas as análises sensoriais foram conduzidas na cidade de Medianeira, situada no oeste do Estado do Paraná. A avaliação hedônica foi conduzida em blocos ao acaso, e os resultados obtidos foram avaliados por meio da análise de variância e teste de comparação de médias de Tukey $(\mathrm{P}<0,05)$. Para os testes de ordenação da preferência, foram utilizadas as tabelas $(\mathrm{P}<0,05)$ de NEWELL \& MACFARLANE (1987).

\section{RESULTADOS E DISCUSSÃO}

Os resultados obtidos para as características físico-químicas dos cafés provenientes dos diversos processos foram diferentes. A umidade dos grãos verdes foi de 9,38\% e decresceu (Tabela 1) com o aumento do tempo de torra. A umidade inicial baixa dos grãos colaborou com a preservação destes durante o período do experimento. VITORINO et al. (2001) explica que, durante a reação de pirólise, ocorre a formação e a liberação de água e que, por esse motivo, a curva de variação do teor de umidade representa o balanço da água originalmente presente nos grãos verdes, da água resultante do processo de pirólise e dos compostos voláteis liberados.

Nas duas primeiras torras, houve desenvolvimento de cor amarela, sendo denominadas torras claras; a terceira desenvolveu uma coloração marrom avermelhada, podendo ser considerada uma torra média escura e, na quarta, a coloração marrom escura tendendo a preto identificou uma torra bem escura. O Phototvolt indicou um percentual de reflexão da luz maior para os pós de café mais claros (Tabela 1), a correlação desta medida com a cor pode ser explicada. A luz branca é composta de todas as cores do espectro do arco-íris; quando essa luz incide sobre um objeto, certas cores são absorvidas e outras refletidas. A luz refletida pode ser captada pelos olhos e, nesse caso, por esse equipamento. O estudo do percentual refletido pode ser utilizado para determinar a intensidade da cor; quanto mais escura for a torra, menos luz será refletida pelo pó, pois cores escuras absorvem a luz.

O processo de torrefação pode ser dividido em três estágios; secagem, torrefação e resfriamento. No primeiro, ocorre a liberação de água e compostos voláteis dos grãos e a cor muda de verde para amarelo. No segundo, ocorrem reações químicas exotérmicas de pirólise com liberação de gás carbônico, a cor dos grãos varia de marrom claro a escuro devido à caramelização dos açúcares e o seu final é caracterizado pela duplicação do volume dos grãos; nesse ponto, os grãos devem ser resfriados para se evitar a carbonização (SIVETZ \& DESROSIER, 1979).

Tabela 1 - Teores físico-químicos médios das quatro torras utilizadas nos testes sensoriais.

\begin{tabular}{|c|c|c|c|c|c|c|c|c|}
\hline \multirow{2}{*}{$\begin{array}{l}\text { Tempo de } \\
\text { Torra }\end{array}$} & \multirow{2}{*}{$\begin{array}{l}\text { Temperatura } \\
\text { final da torra }\end{array}$} & \multirow{2}{*}{$\begin{array}{l}\text { Perda de peso } \\
\text { dos grãos }\end{array}$} & \multirow{2}{*}{ Umidade } & \multirow{2}{*}{ Cor da torra } & \multicolumn{2}{|c|}{------Moagem fina------ } & \multicolumn{2}{|c|}{-----Moagem Média------ } \\
\hline & & & & & $\mathrm{pH}$ & $\begin{array}{l}\text { Acidez } \\
\text { titulável }\end{array}$ & $\mathrm{pH}$ & $\begin{array}{l}\text { Acidez } \\
\text { titulável }\end{array}$ \\
\hline 16 & 180 & 10,60 & $1,01^{\mathrm{b}}$ & $59,20^{d}$ & $4,4^{\mathrm{Ac}}$ & $309,60^{\mathrm{Bd}}$ & $4,4^{\mathrm{Ac}}$ & $230,40^{\mathrm{Ad}}$ \\
\hline 18 & 190 & 11,25 & $0,80^{\mathrm{ab}}$ & $53,96^{c}$ & $4,3^{\mathrm{Ad}}$ & $266,40^{\mathrm{Bc}}$ & $4,3^{\mathrm{Ad}}$ & $187,20{ }^{\mathrm{Ac}}$ \\
\hline 20 & 210 & 18,65 & $0,73^{a b}$ & $30,72^{b}$ & $5,1^{\mathrm{Ab}}$ & $201,60^{\mathrm{Bb}}$ & $5,1^{\mathrm{Ab}}$ & $165,60^{\mathrm{Ab}}$ \\
\hline 22 & 230 & 22,78 & $0,61^{\mathrm{a}}$ & $17,90^{\mathrm{a}}$ & $5,5^{\mathrm{Aa}}$ & $126,00^{\mathrm{Ba}}$ & $5,5^{\text {Aa }}$ & $158,40^{\text {Аa }}$ \\
\hline
\end{tabular}

As unidades empregadas para a leitura dos valores foram: tempo de torra em minutos, temperatura final ${ }^{\circ} \mathrm{C}$, perda de peso e umidade em $\%$, cor da torra em \% de reflexão da luz emitida e acidez titulável em mL de $\mathrm{NaOH} 0,1 \mathrm{~N}$ por $100 \mathrm{~g}$ de amostra. Médias, dentro das mesmas unidades de medida, seguidas por letras minúsculas distintas nas colunas e maiúsculas distintas entre colunas, diferem estatisticamente em nível de 5\% de probabilidade de erro pelo teste de Tukey. 
Nas torras onde a temperatura final ficou abaixo de $190^{\circ} \mathrm{C}$, a coloração final permaneceu na tonalidade amarela e a perda de peso foi pequena (Tabela 1). Podemos dizer que essas torras permaneceram no primeiro estágio de torra. Quando a torra atingiu $210^{\circ} \mathrm{C}$, ocorreu a pirólise e a liberação de $\mathrm{CO}_{2}$, o que pode ser notado pelo aumento na perda de peso dos grãos e pela cor final obtida, que foi de tonalidade marrom. Quando a temperatura aumentou até $230^{\circ} \mathrm{C}$, houve a liberação de grande quantidade de óleo, que recobriu totalmente os grãos, correspondendo ao final do segundo estágio de torra. Os principais produtos da pirólise, segundo BOAS et al. (2001), são os açúcares caramelizados, os carboidratos, o ácido acético e seus homólogos aldeídos, cetonas, furfural, ésteres, ácidos graxos, aminas, $\mathrm{CO}_{2}$ e sulfetos. Todos esses constituintes contribuirão para um desenvolvimento do sabor do café.

Foram gastos $153,36 \mathrm{~mL}$ de $\mathrm{NaOH} 0,1 \mathrm{~N}$ $100 \mathrm{~g}^{-1}$ de amostra de grãos crus e, com a torra, a acidez titulável aumentou (Tabela 1), em função da formação de ácidos, principalmente, a partir de carboidratos, quando estes são submetidos à decomposição térmica e reduzidos a ácidos carboxílicos e $\mathrm{CO}_{2}$ (LOPES et al., 2000). Os valores de acidez titulável encontrados apresentaram uma tendência de redução com o aumento do tempo de torra, que foi diferente $(\mathrm{P}<0,05)$ entre os tempos de torra e entre as diferentes moagens. O ácido clorogênico é hidrolisado a ácidos caféico e quínico, cujos sabores são mais amargos e adstringentes do que dos outros ácidos, pois seu grupo cíclico é um fenol (MENEZES, 1994). A moagem mais fina apresentou valores de acidez mais elevados $(\mathrm{P}<0,05)$ do que os encontrados para a moagem média, o que pode ter sido devido à maior facilidade de extração dos ácidos presentes quando a amostra se apresentava pulverizada em partículas menores. Isso provavelmente acontece também no preparo do café, e essa diferente quantidade de ácidos liberada pelos pós de diferentes texturas pode influenciar na acidez do líquido extraído. Geralmente pHs entre 4,9 e 5,2 são adequados para um sabor mais aceito no café. O pH dos grãos foi de 5,2, ou seja, maior que o encontrado nas três primeiras torras. Isso mostra que o $\mathrm{pH}$ tende a baixar no início do processo de torra e aumentar logo a seguir; assim sendo, quanto maior o tempo de torra mais elevado tende a ser o pH. Houve diferença estatística entre os pHs verificados nos diferentes tempos de torra, porém não houve diferença $(\mathrm{P}<0,05)$ entre os $\mathrm{pHs}$ encontrados para os diferentes graus de moagem. A acidez dos grãos crus foi menor do que a encontrada para os grãos nas torras mais claras, e muito próxima da encontrada para a torra mais escura. Isso se deve aos processos químicos que acontecem nos grãos durante o processo de torra. SIVETZ (1971) explica que os ácidos voláteis são formados, comumente, durante a torra, pela pirólise de açúcares, carboidratos e proteínas, e os não-voláteis, já existentes no café verde, decompõem-se com o aumento do tempo de torra.

A população entrevistada era composta de $59 \%$ de mulheres e $41 \%$ de homens, sendo que nenhuma tendência diferenciada foi notada entre os sexos ao se analisar as respostas separadamente. As faixas etárias não influenciaram nas respostas e apenas $4 \%$ dos jovens entre 18 e 28 anos não eram apreciadores de café. Dentre os apreciadores de café, apenas $4 \%$ tomam o produto esporadicamente. Alguns com mais de 40 anos afirmaram que não consomem por problemas de saúde e proibição médica. Os demais apresentaram a seguinte distribuição de consumo: uma vez ao dia (28\%), duas vezes ao dia (22\%), três vezes ao dia (4\%) e várias vezes ao dia (30\%), o que indicou que a tendência de consumo foi de uma e duas vezes, possivelmente porque aquelas pessoas que têm o café disponível, seja em casa, ou no trabalho, acabam consumindo mais vezes.

Em relação à forma de consumo, foi observada uma distribuição equilibrada entre o café puro (43\%) e o com leite (46\%), não havendo preferência quanto a uma ou a outra dessas formas para $11 \%$ dos entrevistados. Quanto à moagem, na análise da aparência dos pós, $89 \%$ das pessoas preferiram a granulometria fina, $9 \%$ a média, sendo que $2 \%$ demonstraram indiferença. Os avaliadores acreditam que o pó mais fino rende mais.

Os resultados de ordenação de aparência global e aroma podem ser visualizados na tabela 2 . Os entrevistados afirmam que quanto mais torrado o café melhor, pois proporciona maior rendimento. Apesar de preferirem os pós mais torrados aos mais claros, $40 \%$ da população considera que o pó de café mais escuro seria excessivamente amargo, por isso optaram pelo produto da torra de 20 minutos como preferido; esse café, de torra média escura, foi ordenado pelos provadores em primeiro ou em segundo lugar. Uma faixa expressiva da população (58\%) escolheu a torra mais escura como a preferida, citando que café quanto mais escuro melhor, demonstrando que se preocupam mais com o rendimento do produto do que com a qualidade sensorial, porém $10 \%$ dos provadores preteriram essa torra até pelas mais claras. 
Tabela 2 - Resultados obtidos nos testes sensoriais de ordenação da preferência em relação à aparência global e ao aroma das amostras e notas médias obtidas no teste hedônico da bebida.

\begin{tabular}{|c|c|c|c|c|}
\hline \multirow{2}{*}{$\begin{array}{l}\text { Tempo de torra } \\
\text { (Minutos) }\end{array}$} & \multicolumn{2}{|c|}{---Teste de ordenação da preferência*-- } & \multicolumn{2}{|c|}{----------------Teste hedônico**--------------- } \\
\hline & Aparência global & Aromas & $\begin{array}{c}\text { Granulometria de } \\
\text { moagem fina }\end{array}$ & $\begin{array}{l}\text { Granulometria de } \\
\text { moagem média }\end{array}$ \\
\hline 16 & $397^{c}$ & $306^{\mathrm{c}}$ & $4,01^{\mathrm{d}}$ & $4,19^{d}$ \\
\hline 18 & $288^{b}$ & $222^{b}$ & $5,11^{\mathrm{c}}$ & $4,83^{\mathrm{cd}}$ \\
\hline 20 & $160^{\mathrm{a}}$ & $194^{\mathrm{a}}$ & $6,46^{\mathrm{a}}$ & $6,14^{\mathrm{ab}}$ \\
\hline 22 & $155^{\mathrm{a}}$ & $278^{c}$ & $6,10^{\mathrm{b}}$ & $5,38^{\text {bc }}$ \\
\hline
\end{tabular}

*Somas seguidas por letras distintas, em cada coluna, diferem estatisticamente em nível de 5\% de probabilidade de erro pelo teste de Tukey. Os valores menores correspondem aos produtos preferidos.

** Comparação de notas dos oito tratamentos médias seguidas por letras distintas diferem estatisticamente em nível de 5\% pelo teste de Tukey. 1= desgostei muitíssimo; 2= desgostei muito, 3= desgostei regularmente, $4=$ desgostei ligeiramente, $5=$ indiferente, $6=$ gostei ligeiramente, 7 = gostei regularmente, 8 = gostei muito, 9 = gostei muitíssimo.

Os 100 provadores que realizaram a análise sensorial hedônica e o teste de ordenação de aromas eram apreciadores de café. Destes, $62 \%$ eram do sexo feminino e $38 \%$ do sexo masculino; $55 \%$ tomavam geralmente o café puro e 31\% preferiam o café adicionado de leite. As mulheres participaram mais prontamente dos testes e, quando se compararam as preferências, foi observado que $8 \%$ a mais delas preferiram o café puro e $10 \%$ a mais deles preferiram o café com leite.

Em relação à freqüência de consumo, 10\% dos provadores tomam café esporadicamente, 19\% uma vez ao dia, $20 \%$ duas vezes, $18 \%$ três vezes e $33 \%$ várias. Houve diferença entre as amostras e entre os provadores $(\mathrm{P}<0,05)$. A diferença observada entre os degustadores se deve ao gosto pessoal, já as encontradas entre as amostras (Tabela 2) evidenciam a preferência em relação às torras e às moagens testadas. Houve preferência pelo aroma e sabor da amostra com torra de 20 minutos, sendo indiferente sua granulometria de moagem, em cada um dos tempos de torra testados. Nas torras preferidas, as notas obtidas pelas amostras com moagem média foram menores. As maiores notas médias se localizaram entre 5 e 7, o que está de acordo com SOUZA et al. (2004). Os consumidores não demonstram suas preferências de forma explícita; dessa forma, é interessante observar os percentuais de aceitação (notas de 6 e 9) e de rejeição (notas entre 1 e 4 ) dos produtos (Figura 1).

A torra mais clara (A) foi rejeitada em média por $60 \%$ dos provadores; na torra seguinte (B), a média de rejeição reduziu-se para 42,5\%. Nas duas torras mais escuras (C e D), as médias de aceitação foram de 74,5\% e $62 \%$, respectivamente. A granulometria de moagem não foi responsável por grandes diferenças na aceitação, em nenhuma da torras. Houve uma reclamação constante de que os cafés resultantes das duas torras mais escuras eram muito fortes. Isso pode ter sido devido ao costume do consumidor de utilizar menos pó no preparo do produto, ou por ser café arábica puro, sem mistura com o robusta, o que seria pouco comum dos produtos geralmente consumidos pela população e que segundo PEREIRA et al. (2000), pode ocasionar aumento da adstringência da bebida.

Para o gosto da população do oeste do Paraná, a torra deve ir até o ponto onde ocorre a pirólise, com a conseqüente liberação de $\mathrm{CO}_{2}$, e que esta seja interrompida quando a temperatura passar de $210^{\circ} \mathrm{C}$. Caso a temperatura alcance $230^{\circ} \mathrm{C}$, uma grande quantidade de óleo recobriria os grãos, reduzindo a aceitação do produto. Este ponto é erroneamente descrito por muitos como ponto ideal da torra brasileira. Durante as análises, apenas a aparência global do pó resultante desse processamento foi bem aceita, o aroma e o sabor da bebida foi menos preferida e diferente estatisticamente da torra anterior, um pouco mais leve, no que diz respeito ao seu aroma e sabor.

\section{CONCLUSÕES}

A torra que apresentou aparência global, aroma e sabor preferidos foi a média escura. Com relação à aparência global dos pós de café, a moagem fina foi preferida. Não se notou interferência da granulometria de moagem, quando se avaliou o sabor do café.

\section{AGRADECIMENTOS}

Os autores agradecem à Empresa Café Iguaçu, localizada na cidade de Cornélio Procópio, na pessoa do Sr. Fábio Lupreato Marques, Engenheiro de Produto, pela realização das análises de coloração dos pós de café, no equipamento Photovolt modelo 577 de propriedade daquela empresa. 


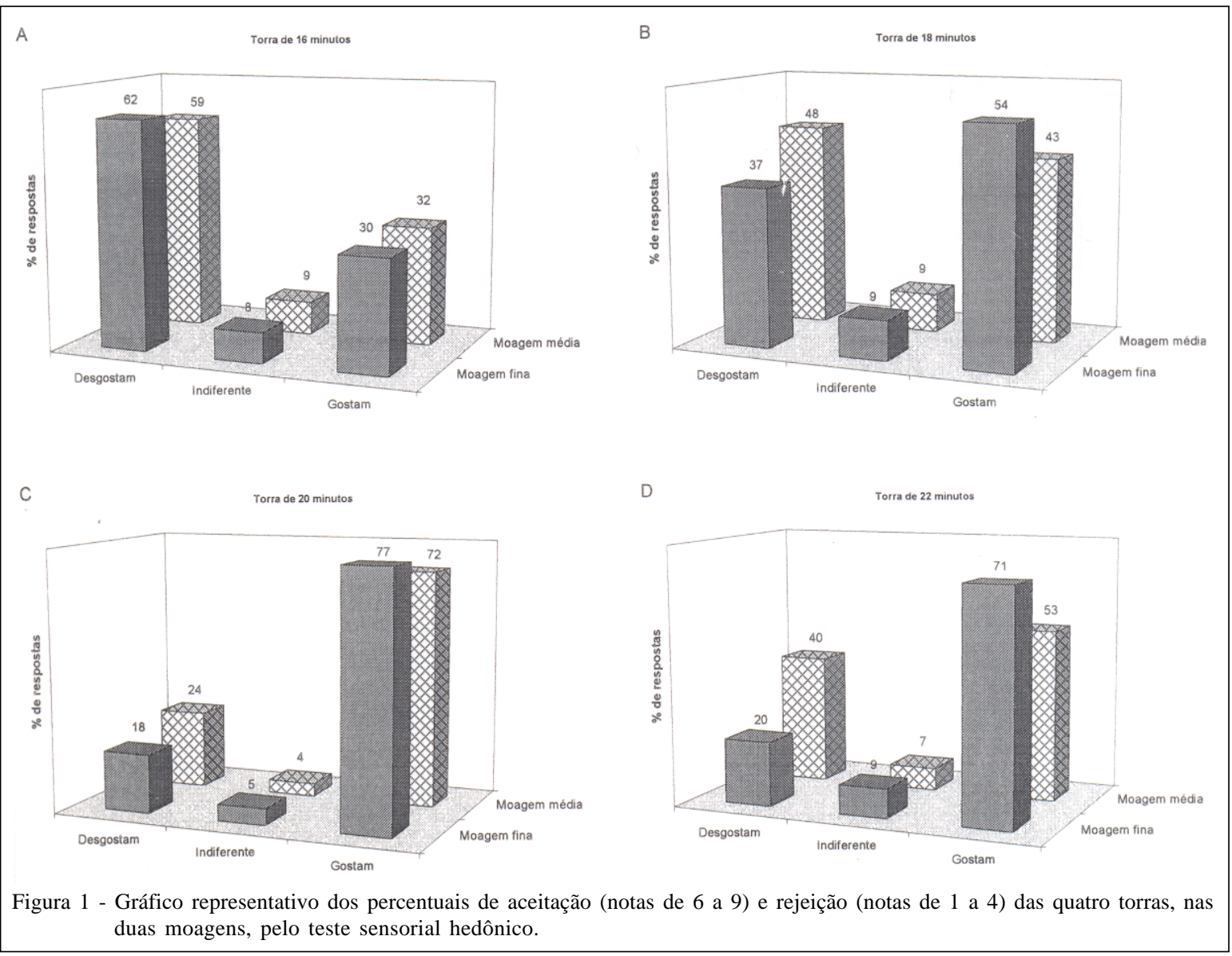

\section{REFERÊNCIAS}

ABIC. Sabor do café - dicas de preparação. Capturado em 20 jun. 2004. Online. Disponível na Internet http:// www.abic.com.br/scafe_dicas.html.

ASSOCIATION OF OFFICIAL ANALYTICAL CHEMISTS. Coffee and Tea. In: Official methods of analyses of the Association of Official Analytical Chemists. 15.ed. Washington, 1996. Cap.30, p.30-32.

BOAS, B.M.V. et al. Seleção de extratores e tempo de extração para determinação de açucares em café torrado. Ciência Agrotecnologia, Lavras, v.25, n.5, p.1169-1173, 2001.

BRASIL. Instrução normativa $\mathrm{n}^{\circ} 8$, de 11 de junho de 2003. Regulamento técnico de identidade e de qualidade para a classificação do café beneficiado grão cru. Capturado em 06 dez. 2004. Online. Disponível na Internet http:// www.abic.com.br/arquivos/leg_ instnormativa08_2003. pdf.

CLARKE, R.J.; MACRAE, R. Coffee chemistry. Londres: Elsevier Applied Science, 1990. V.1, 320p.

CORTEZ, J.G. Efeito de espécies e cultivares e do processamento agrícola e industrial nas características da bebida do café. 2001. 71f. Tese (Doutorado em Agronomia, área de concentração fitotecnia) - Curso de Pós-graduação em Agronomia, Escola Superior de Agricultura Luiz de Queiroz.
CRISTOVAM, E. et al. Gender preference in hedonic ratings for espresso and espresso-milk coffees. Food Quality and Preference, Londres, v.11, n. 6, p.437-444, 2000.

DELLA MODESTA, R.C. et al. Desenvolvimento e validação do perfil sensorial para a bebida de café brasileiro. Rio de Janeiro: Embrapa Agroindústria de Alimentos, 1999. 37p. (Boletim de pesquisa; n.22).

FARIA, E.V. et al. Expectativas e preferências do consumidor em relação ao café torrado e moído - Parte 1: teste do produto em 10 cidades brasileiras. In: SIMPÓSIO DE PESQUISA DOS CAFÉS DO BRASIL, 2000, Poços de Caldas. Resumos expandidos... Brasília: Embrapa Café; Belo Horizonte: Minasplan, 2000. V.2, 1490p. p.381-384.

GUERRERO, L. Estúdios de consumidores: análisis de los errores más habituales. In: ALMEIDA, T.C.A. et al. Avanços em análise sensorial. São Paulo: Varela, 1999. 286p. p.121129.

ILLY, A.; VIANI, R. Espresso coffee: the chemistry of quality. 2.ed. San Diego: Academic, 1996. 253p.

LOPES, L.M.V. et al. Teor de sólidos solúveis totais, acidez total titulável e $\mathrm{pH}$ de grãos crus e torrados de sete cultivares de café (Coffea arabica L.) e suas variações como o processo de torração. In: SIMPÓSIO DE PESQUISA DOS CAFÉS DO 
BRASIL, 2000, Poços de Caldas. Resumos expandidos... Brasília: Embrapa Café; Belo Horizonte: Minasplan, 2000. V.2, 1490p. p.748-751

LUNA, R.M. et al. Preferência do consumidor no processo de compra de café: pesquisa de marketing no mercado paulista. In: SIMPÓSIO DE PESQUISA DOS CAFÉS DO BRASIL E WORKSHOP INTERNACIONAL DE CAFÉ \& SAÚDE, 2003, Porto Seguro. Anais... Brasília: Embrapa Café, 2003. 447p. p.384-385.

MENEZES, H.C. Variação dos monoisômeros e diisômeros do ácido cafeoilquínico com maturação de café. 1994. 171f. Tese (Doutorado em Tecnologia de Alimentos) - Curso de Pós-graduação em Tecnologia de Alimentos, Universidade Estadual de Campinas.

MORAES, R.C. de P.; TRUGO, L.C. Efeito da torrefação e da granulometria na composição química do café. In: SIMPÓSIO BRASILEIRO DE PESQUISA DOS CAFÉS DO BRASIL, 2001, Vitória. Anais... Brasília: Embrapa Café, 2001. CD-ROM. p.1511-1517.

MOURA, S.C.S.R. et al. Obtenção de ciclos de torração de cafés brasileiros para guia prático de torrefações nacionais Parte I. In: SIMPÓSIO BRASILEIRO DE PESQUISA DOS CAFÉS DO BRASIL, 2001, Vitória. Anais... Brasília: Embrapa Café, 2001. CD-ROM. p.1560-1567.

NEWELL, G.J.; MACFARLANE, J.D. Expanded tables for multiple comparison procedures in the analysis of ranked data. Journal o Food Science, Chicago, v.52, n.6, p.1721-1725 1987.
PEREIRA, R.G.F.A. et al. Avaliação química de misturas em diferentes proporções de café arábica (Coffea arábica L.), bebida mole, e Conilon (Coffea canephora Pierre). In: SIMPÓSIO DE PESQUISA DOS CAFÉS DO BRASIL, 2000, Poços de Caldas. Resumos expandidos... Brasília: EMBRAPA Café; Belo Horizonte: Minasplan, 2000. V.2, 1490p. p.643-645.

PINTO, N.A.V.D. et al. Avaliação dos polifenois e açucares em padrões de bebida do café torrado tipo expresso. Revista Brasileira de Agrociência, Pelotas, v.7, n.3, p.193-195, 2001.

SCHWARTZBERG, H.G. Coffee. In: WILLEY, J. et al. Wiley encyclopedia of food science and technology. 2.ed. 1999. p.354-361. Capturado em 24 mai. 2004. Online. Disponível na Internet http://www.knovel.com/knovel2/Toc.jsp? SpaceID $=10103 \&$ BookID $=681$.

SIVETZ, M. Many variables can influence acidity. Tea \& Coffee: Trade Journal, Nova York, v.141,n.1, p.26-27, 1971.

SIVETZ, M.; DESROSIER, N.W. Coffee technology. Westport: Avi, 1979. 716p.

SOUZA, V.F. et al. Influência dos fatores demográfico e geográfico na preferência da bebida de café no Estado do Rio de Janeiro. Brazilian Journal of Food Technology, Campinas, v.7, n.1, p.1-7, 2004.

VITORINO, M.D. et al. Modelagem da evolução de umidade e voláteis dos grãos de café durante a torra. In: SIMPÓSIO BRASILEIRO DE PESQUISA DOS CAFÉS DO BRASIL, 2001, Vitória. Anais... Brasília: Embrapa Café, 2001. CD-ROM. p.1551-1559. 